\title{
Hubungan Penanganan Beban Manual dengan Nyeri Punggung Bawah Pada Karyawan PT. Perdagangan dan Perindustrian Bangkinang
}

\section{The Correlation between Manual Handling and Low Back Pain}

\author{
Erna Ariyani ${ }^{1}$ \\ ${ }^{1)}$ Program Studi Magister Ilmu Kesehatan Masyarakat STIKes Hang Tuah Pekanbaru \\ Jl. Mustafa Sari No. 5 Tangkerang Selatan Pekanbaru \\ Alamat Korespondensi: Jl. Utama No. 150 C, Simpang Tiga, Pekanbaru \\ Email: erna.abdillah@gmail.com
}

\begin{abstract}
ABSTRAK
Penangan Beban Manual (PBM) merupakan salah satu faktor risiko terjadinya keluhan Nyeri Punggung Bawah (NPB). NPB adalah salah satu Gangguan Otot Tulang Rangka (GOTRAK) pada daerah punggung. Tujuan penelitian ini untuk mengetahui hubungan lingkungan kerja ergonomis (postur janggal dan pengerahan kekuatan otot dalam PBM) serta kapasitas kerja (kebiasaan merokok, masa kerja dan usia) dengan keluhan NPB pada karyawan PT.Perdagangan dan Perindustrian Bangkinang. Jenis penelitian ini adalah kuantitatif analitik observasional dengan menggunakan desain studi penampang analitik (analitic crosssectional study). Penelitian dilakukan pada bulan Maret 2016 hingga September 2016, jumlah sampel sebanyak 150 orang. Pengambilan data melalui observasi langsung, wawancara dan pengukuran dengan menggunakan metode analisis sikap kerja REBA. Analisis data dilakukan secara univariat, bivariat, dan multivariat. Hasil penelitian diperoleh proporsi keluhan NPB pada karyawan PT.Perdagangan dan Perindustrian Bangkinang adalah 61,3\% dari sampel. Estimasi proporsi pada populasi dengan derajat kepercayaan 95\% (61,222-61,378\%). Variabel yang berhubungan dengan keluhan NPB adalah postur janggal dalam PBM (OR: 6,254; 95\% CI: 2,155-18,150) dan usia (OR: 4,766; 95\% CI: 4,151-21, 153). Disarankan kepada manajemen perusahaan untuk mengurangi kegiatan PBM dengan mengganti penanganan secara mekanis, melakukan pelatihan tentang teknik PBM yang aman dan benar bagi karyawan, melakukan rotasi penempatan unit kerja secara berkala.
\end{abstract}

Kata Kunci:PBM, NPB, postur janggal, REBA

\begin{abstract}
Manual handling is a risk factor of low back pain (LBP) among the workers. LBP is one of Work Musculoskeletal Disorders (WMDs). The first aim of research was to identify the correlation between work environment (awkward posture and force) and LBP's complaining among Bangkinang Company's workers. The second aim of research was to identify correlation between work capacities (years of service, age and smoking habits) and LBP's complaining among Bangkinang Company's workers. The research method was an observational quantitative. The design of the study was a cross-sectional study. Respondents of this research was 150 workers. Observation, interview and measurements were used to collect data. Measurements of awkward posture were used REBA sheets. Data was analyzed by univariate, bivariate and multivariate. The result of this research was $61.3 \%$ proportion of LBP's complaining (CI $95 \%$, estimation proportion $61,222-61,378 \%)$. The conclusion of research is there are correlation of awkward posture (OR: 6,254; 95\% CI : 2,155-18,150) and age (OR: 4,766; 95\% CI: 4,151-21,153). Author Suggestion is replacing manual handling with mechanical technique, training about manual handling and rotation of job position.
\end{abstract}




\section{PENDAHULUAN}

Nyeri Punggung Bawah (NPB) adalah suatu sindroma nyeri atau ketidaknyamanan pada regio punggung bagian bawah yang dapat disebabkan oleh berbagai sebab, bersifat akut, subakut atau kronik (Tresnaningsih, 2015; Pratiwi et al, 2009). Saat ini 90\% kasus NPB bukan lagi disebabkan oleh kelainan organik, melainkan posisi tubuh yang salah dalam bekerja (Wheeler, 2016). Keluhan NPB sering menjadi alasan ketidakhadiran kerja sehingga menurunnya produktivitas dan prestasi kerja individu, sehingga menjadi masalah dalam kesehatan dan ekonomi (Duthey, 2013).

Penanganan Beban Manual (PBM) adalah semua kegiatan mengangkat, menurunkan, membawa, meletakkan, menahan, mendorong atau menarik dan sebagainya yang dilakukan dengan menggunakan organ tubuh manusia. PBM merupakan salah satu kegiatan yang umum dilakukan dalam dunia pekerjaan. Banyak penelitian yang menyebutkan bahwa PBM merupakan sumber utama terjadinya Gangguan Otot Tulang Rangka Akibat Kerja (GOTRAK). GOTRAK dapat terjadi dimana-mana, misalnya di daerah leher : Tension Neck Syndrome; di daerah bahu Rotator Cuff Tendinitis; di daerah punggung bawah : Low Back Pain/Nyeri Punggung Bawah; di daerah pergelangan tangan : Carpal Tunnel Syndrome (Tresnaningsih, 2015).

Menurut data dari Departemen Tenaga Kerja Amerika Serikat tahun 1990, kejadian cedera tulang belakang adalah kecelakaan kerja yang umum terjadi dan paling banyak membutuhkan biaya untuk pengobatan. Sekitar $60 \%$ penyebab dari cedera ini adalah pengerahan tenaga yang berlebihan oleh tulang belakang saat mengangkat dan mengangkut barang, 20\% mendorong atau menarik barang, dan 20\% akibat meletakkan barang. Pekerja yang melakukan kegiatan PBM secara terus menerus berisiko mengalami cedera punggung 8 kali lipat dibandingkan pekerja yang hanya mengangkat barang tidak terus menerus (Kumar, et al., 2004; Santoso. 2006).

Pada penelitian yang dilakukan PERDOSSI (Persatuan Dokter Spesialis Saraf Indonesia) di 14 rumah sakit pendidikan Indonesia, menunjukkan jumlah penderita nyeri $25 \%$ dari total kunjungan, dimana 18, 37\% adalah penderita NPB (Meliala,2004). Di Rumah Sakit Umum Daerah (RSUD) Arifin Achmad Pekanbaru, jumlah penderita NPB termasuk peringkat ke 5 dari seluruh pasien yang dirawat (Riau Pos, 2012; Rinaldi et al., 2015).

PT. Perdagangan dan Perindustrian Bangkinang (PT. PP Bangkinang) merupakan salah satu pabrik karet yang berada di Pekanbaru. Proses pengolahan crumb rubber, dimulai dari pengumpulan bahan baku karet dari para petani karet. Bahan baku yang telah terkumpul ditimbun (Bokar) $\rightarrow$ dipotong $\rightarrow$ pembersihan awal $\rightarrow$ macro blending $\rightarrow$ micro blending $\rightarrow$ pengeringan sekitar 4 sampai dengan 5 minggu penjemuran $\rightarrow$ peremahan $\rightarrow$ proses pengeringan secara mekanis $\rightarrow$ pendinginan $\rightarrow$ pengemasan $\rightarrow$ penyimpanan. Dalam proses pengolahan crumb rubber banyak kegiatan PBM seperti mengangkat beban bahan baku, menarik dan medorong timbunan blengket untuk dijemur, serta meletakkan hasil pengolahan kedalam kotak penyimpanan yang dilakukan karyawan saat bekerja.

Berdasarkan kondisi tersebut, peneliti tertarik untuk melakukan penelitian dengan judul "Hubungan Penanganan Beban Manual terhadap keluhan Nyeri Punngung Bawah pada karyawan PT. Perdagangan dan Perindustrian Bangkinang Pekanbaru Tahun 2016.”

\section{METODE PENELITIAN}

Jenis Penelitian ini adalah analitik kuantitatif dengan jenis desain Studi Penampang Analitik (analytic cross-sectional). Penelitian ini dilakukan di wilayah kerja PT.Perdagangan dan Perindustrian Pekanbaru pada Maret 2016 - September 2016. Populasi dalam penelitian ini adalah seluruh karyawan PT. Perdagangan dan Perindustrian Pekanbaru yang berjumlah 250 orang, sedangkan sampel dalam penelitian ini adalah 150 orang yang diambil secara random sampling. Dalam analisis data digunakan analisa univariat, bivariat dan multivariat.

\section{HASIL}

\section{Analisis Univariat}

Berdasarkan kuesioner yang dikumpulkan dari 150 responden diperoleh data (Tabel 1) tentang pekerja yang pernah mengalami keluhan NPB adalah 61,3\% dan yang tidak pernah mengalami keluhan NPB adalah 38,7\%. 
Tabel 1. Distribusi variabel independen pada penelitian kuantitatif analitik tentang hubungan PBM dengan keluhan NPB pada pekerja PT. PP Bangkinang di Pekanbaru tahun 2016

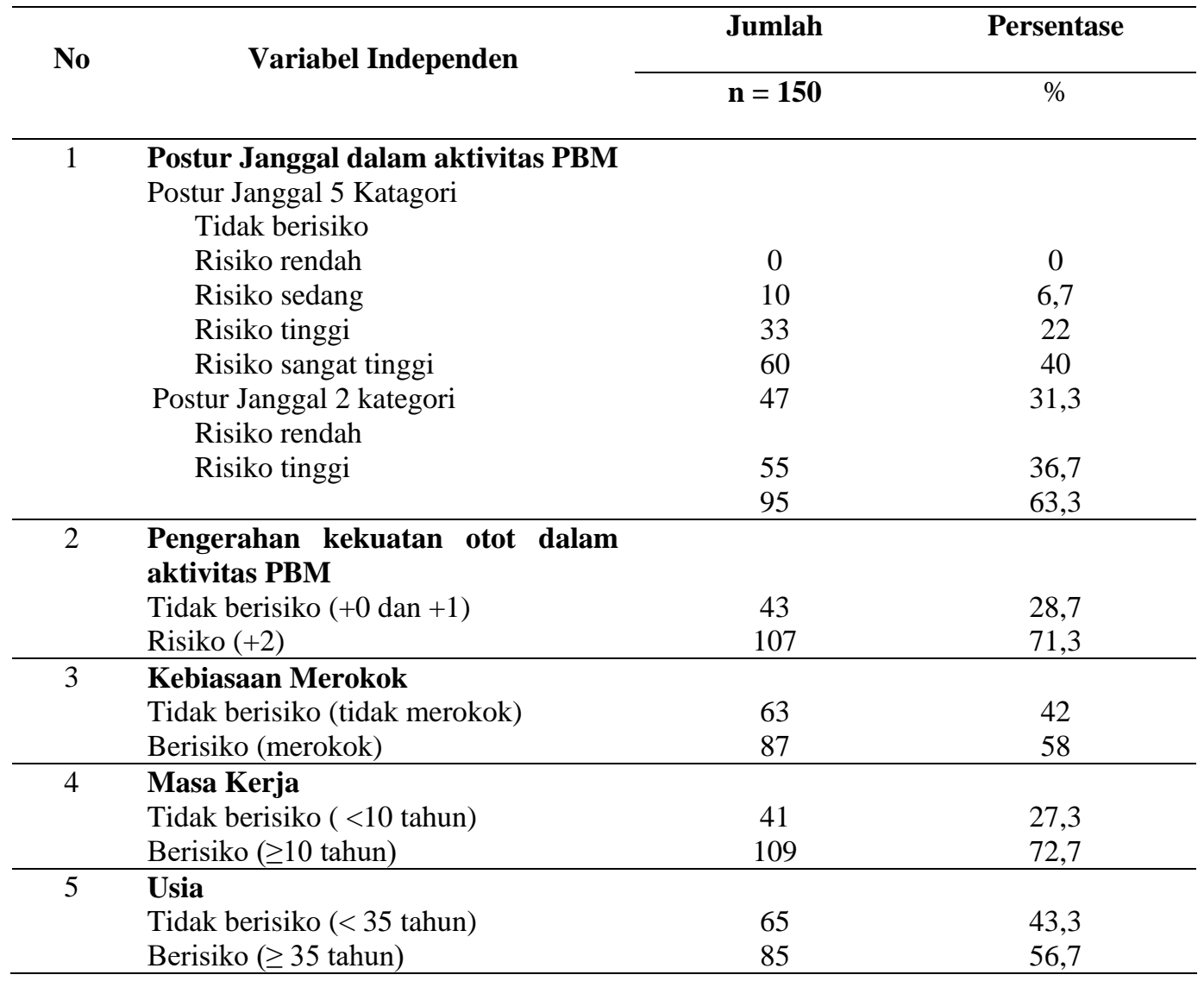

\section{Analisis Bivariat}

Dari analisis bivariat (Tabel 2) didapatkan hasil dari 5 variabel independen, ada 3 yang berhubungan signifikan $(\mathrm{p}<0,05)$ dengan keluhan NPB pada karyawan PT.Perdagangan dan Perindustrian Bangkinang, yaitu postur janggal dalam PBM ( $p$ value $<0,001)$, masa kerja ( $p$ value $=0,001)$ dan usia $(p$ value $=0,001)$.

Tabel 2. Hubungan beberapa variabel independen dengan keluhan NPB padapekerja PT.PP Bangkinang di Pekanbaru tahun 2016

\begin{tabular}{|c|c|c|c|c|c|}
\hline \multirow{3}{*}{$\begin{array}{c}\text { Variabel } \\
\text { Independen dan } \\
\text { katagori }\end{array}$} & & Keluhar & & \multirow{3}{*}{ P Value } & \multirow{3}{*}{ POR $(95 \% \mathrm{CI})$} \\
\hline & $\begin{array}{l}\text { Tidak } \\
\text { NPB } \\
\end{array}$ & NPB & Jumlah & & \\
\hline & n (\%) & n (\%) & n (\%) & & \\
\hline $\begin{array}{l}\text { Postur Janggal } \\
\text { dalam PBM } \\
\text { Risiko rendah } \\
\text { Risikotinggi }\end{array}$ & $\begin{array}{l}27(62,8) \\
31(29,0)\end{array}$ & $\begin{array}{l}16(37,2) \\
76(71,0)\end{array}$ & $\begin{array}{l}55(100) \\
95(100)\end{array}$ & $<0,001$ & $\begin{array}{c}4,137 \\
(1,962)\end{array}$ \\
\hline \multirow[t]{2}{*}{$\begin{array}{l}\text { Pengerahan } \\
\text { kekuatan } \\
\text { dalam PBM } \\
\text { Tidak berisiko } \\
\text { Risiko } \\
\text { Kebiasaan }\end{array}$} & $\begin{array}{l}18(40,9) \\
40(37,7) \\
\end{array}$ & $\begin{array}{l}25(59,1) \\
67(62,3) \\
\end{array}$ & $\begin{array}{c}43(100) \\
107(100) \\
\end{array}$ & \multirow[t]{2}{*}{0,858} & $\begin{array}{c}1,742 \\
(0,557-2,343)\end{array}$ \\
\hline & & & & & \\
\hline
\end{tabular}




\begin{tabular}{lccccc}
\hline $\begin{array}{l}\text { Merokok } \\
\text { Tidak berisiko }\end{array}$ & $22(34,9)$ & $41(65,1)$ & $63(100)$ & 0,527 & 0,760 \\
Berisiko & $36(41,4)$ & $51(58,6)$ & $87(100)$ & & $(0,389-1,487)$ \\
\hline Masa Kerja & & & & & \\
$\begin{array}{l}\text { Tidak berisiko } \\
\text { Berisiko }\end{array}$ & $31(75,6)$ & $10(24,4)$ & $41(100)$ & 0.001 & 9,415 \\
\hline Usia & $27(24,8)$ & $82(75,2)$ & $109(100)$ & & $(4,085-21,699)$ \\
$\begin{array}{l}\text { Tidak berisiko } \\
\text { Berisiko }\end{array}$ & $43(66,2)$ & $22(33,8)$ & $65(100)$ & 0,001 & 9,121 \\
\hline
\end{tabular}

\section{Analisis Multivariat}

Untuk analisis multivariat dilakukan beberapa tahapan yang pertama yaitu seleksi bivariat untuk mengetahui variabel mana yang akan dimasukkan kedalam pemodelan multivariat. Selanjutnya pemeriksaan counfounding (perubahan OR $>10 \%$ ) dengan mengeluarkan variabel yang pvaluenya $\geq 0,05$ secara bertahap dari nilai pvalue yang terbesar. Pada penelitian ini didapatkan hasil pemodelan akhir variabel yang berhubungan dengan signifikan terhadap keluhan NPB yaitu postur janggal dalam PBM, kekuatan pengerahan otot dalam PBM, masa kerja dan Usia

Tabel 3. Analisis multivariat terakhir hubungan PBM dengan keluhan NPB pada karyawan PT.PP Bangkinang di Pekanbaru tahun 2016

\begin{tabular}{|c|c|c|c|}
\hline Variabel independen & P Value & POR & $(95 \% \mathrm{CI})$ \\
\hline Postur janggal dalam PBM & 0,001 & 6,254 & $(2,155-18,150)$ \\
\hline $\begin{array}{l}\text { Pengerahan kekuatan otot } \\
\text { dalam PBM }\end{array}$ & 0,287 & 0,552 & $(0,185-1,649)$ \\
\hline Masa Kerja & 0,050 & 3,116 & $(0,998-9.729)$ \\
\hline Usia & 0.003 & 4,766 & $(4,151-21,153)$ \\
\hline
\end{tabular}

\section{PEMBAHASAN}

\section{Postur Janggal dalam PBM}

Pada penelitian ini ditemukan, bahwa postur janggal dalam PBM berhubungan 6 kali untuk mengalami keluhan NPB pada karyawan PT.PP Bangkinang Pekanbaru (CI 95 \%:2,155 18,150. Penelitian ini sejalan dengan teori Adams (1989), postur janggal saat bekerja dapat menyebabkan NPB. Menurut Health Safety Environment (2016) aktivitas PBM terkait postur janggal memaksa pekerja menggunakan lebih banyak tenaga untuk melakukan pekerjaan karena tidak sesuai dengan posisi alami tubuh. Bekerja dalam postur janggal akan meningkatkan tenaga dan kekuatan otot yang digunakan untuk menyelesaikan tugas dan menyebabkan penekanan pada tendon, saraf dan pembuluh darah (Tresnaningsih, 2015). Posisi kerja yang tidak benar dan dipaksakan dapat menimbulkan kelelahan pada otot sehingga kerja menjadi tidak efisien. Dalam jangka waktu yang lama dapat menyebabkan gangguan fisik dan psikologis dengan keluhan yang dirasakan pada punggung (Nurmianto, 2004). Posisi kerja yang tidak ergonomis atau disebut dengan postur janggal yang banyak ditemukan dalam aktivitas PBM akan menjadi faktor risiko penyebab terjadinya NPB sehingga timbul keluhan NPB. 


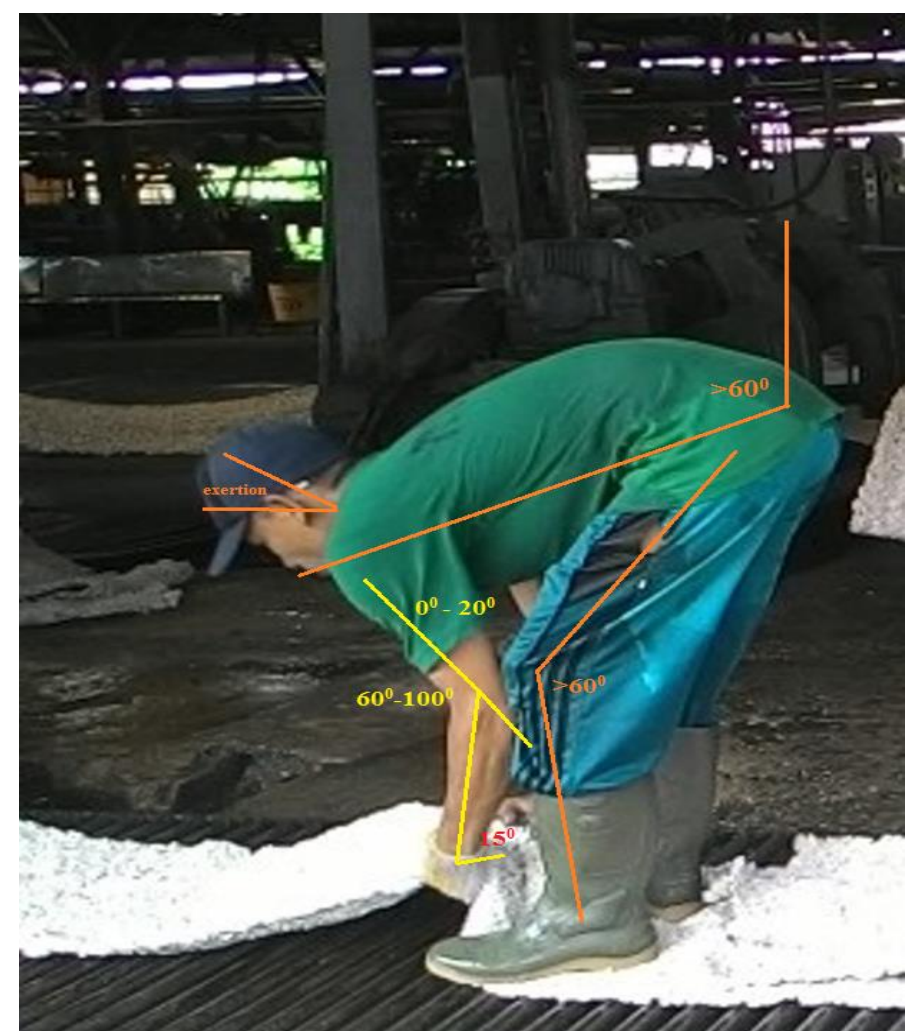

\begin{tabular}{|l} 
REBA ASSESSMENT \\
Neck Score $:+2$ \\
Trunk Score $:+4$ \\
Leg Score: $+1+2=3$ \\
Posture Score $A: 7$ \\
Berat beban $6-8 \mathrm{~kg}$ \\
Force/ load score: +1 \\
Score A : 8 \\
Upper arm score: +1 \\
Lower arm score: +2 \\
Wrist score $:+2$ \\
Posture score B: 2 \\
Coupling Score $:+2$ \\
Score B $: \mathbf{4}$ \\
Table C score $: \mathbf{9}$ \\
Activity Score $:+2$ \\
Final REBA Score $: \mathbf{1 1}$ \\
Scoring: Very high risk. \\
Implement change \\
\end{tabular}

Gambar 1. Postur janggal pada saat proses pengolahan crum rubber dan REBA assessment

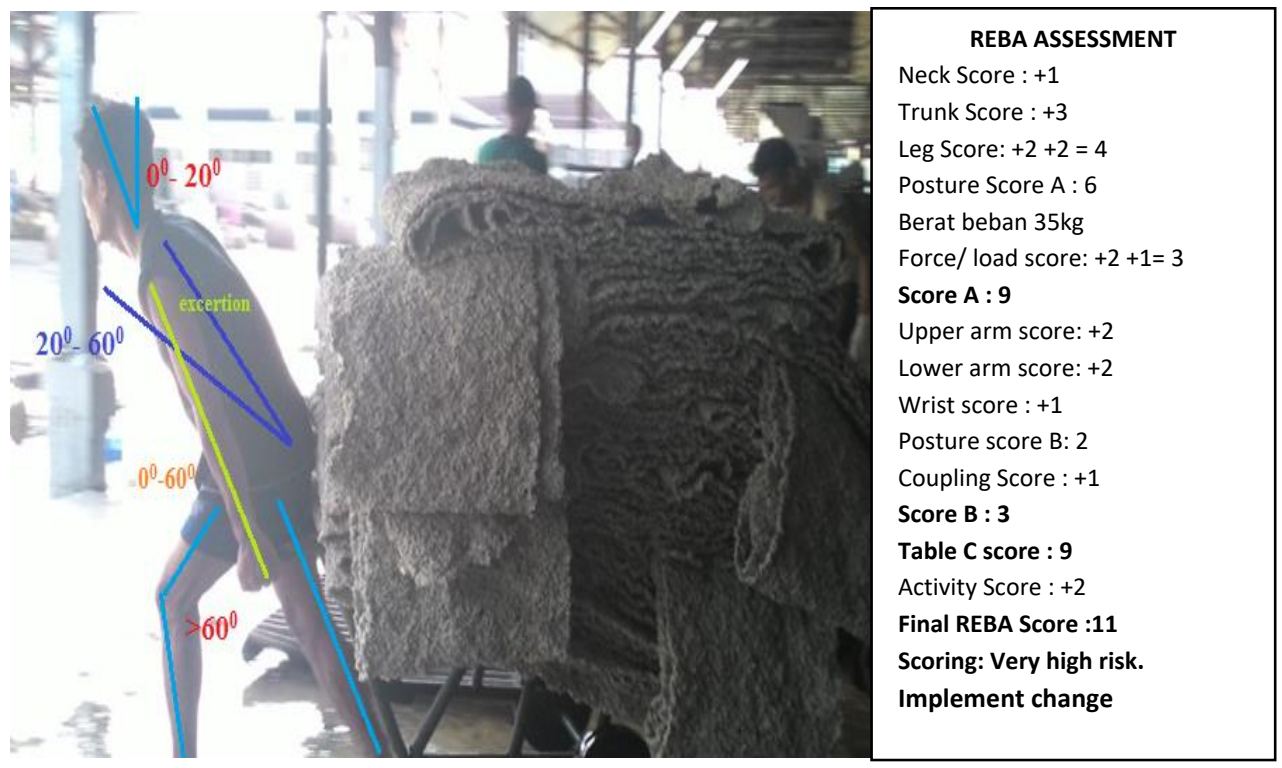

Gambar 2. Postur Janggal saat membawa hasil pengolahan crum rubber untuk dijemur dan REBA assessmeent

Usia

Usia $\geq 35$ tahun berhubungan secara signifikan 4 kali dengan terjadinya keluhan NPB pada pekerja PT.PP Bangkinang Pekanbaru. (CI 95\%:1,676 - 13,553). Hal ini sejalan dengan teori Bull \& Archard (2007) dalam Nurmianto (2004) seiring bertambahnya usia, DIV ini akan kehilangan sebagian besar kadar airnya, menyusut, mengeras dan menyebabkan ruang antar tulang belakang menyempit, sehingga akan mengurangi kemampuannya sebagai bantalan (shock 
absorben) dan mudah mengalami keretakan. Menurut Crock (1970), Usia menjadi salah satu faktor risiko IDD. Kejadian NPB meningkat pada usia 35 dan puncaknya 55 tahun. Terjadi penurunan kekuatan otot dan jaringan penyangga tulang belakang, dan fungsi-fungsi tubuh yang lain sejalan dengan pertambahan usia. Hal ini berakibat bila ada aktifitas yang berlebihan yang melibatkan tulang belakang dan diskusnya, akan meningkatkan risiko terjadinya trauma di area tersebut. Dalam artikel kesehatan tentang NPB yang ditulis oleh Wheeler (2016) Pada proses degeneratif kerentanan akan kebocoran dari annulus fibrosus lebih tinggi, hal ini menyebabkan pelepasan PLA2 dan glutamat, sampai ke lapisan epidural. kelemahan pada DIV akibat proses degeneratif menjadikan DIV lebih rentan terhadap getaran dan kelebihan fisik, yang mengakibatkan kompresi dan merangsang pelepasan histamin dan leukotrien, yang mengubah transmisi impuls saraf. Sehingga sel saraf mengalami iskemia, dan menimbulkan rasa nyeri.

Tabel 4.Hubungan sebab akibat variabel independen dengan keluhan NPB pada pekerja PT.PP Bangkinang Pekanbaru tahun 2016

\begin{tabular}{llcc}
\hline \multirow{2}{*}{ No } & \multicolumn{1}{c}{ Butir kriteria } & \multicolumn{2}{c}{ Variabel independen } \\
\cline { 3 - 4 } & & $\begin{array}{c}\text { Postur Janggal dalam } \\
\text { PBM }\end{array}$ & Usia \\
\hline $\mathbf{1}$ & Temporal & $?$ & + \\
\hline $\mathbf{2}$ & Plausibility (teori) & + & + \\
\hline 3 & $\begin{array}{l}\text { Dose responding } \\
\text { relationship }\end{array}$ & - & 4,766 \\
\hline 4 & $\begin{array}{l}\text { Kekuatan asosiasi } \\
\text { (POR) }\end{array}$ & 6,254 & + \\
\hline 5 & Konsistensi & + & - \\
\hline 6 & Jenis desain & - &
\end{tabular}

\section{IMPLIKASI HASILPENELITIAN}

Variabel Independen yang berhubungan dengan keluhan NPB

Postur Janggal dalam PBM

Dalam penelitian ini ditemukan bahwa postur janggal dalm PBM berpengaruh 6 kali menyebabkan keluhan NPB. Oleh karena itu direkomendasikan kepada manajemen perusahaan untuk 1) Menghindari PBM dan mengupayakan untuk mengganti dengan penanganan mekanis dalam pekerjaan; 2) Mengadakan pelatihan tentang teknik PBM yang aman dan benar bagi karyawan yang melakukan kegiatan; 3) Melakukan rotasi penempatan unit pekerja secara berkala untuk menghindari pekerjaan monoton dengan masa kerja yang lama; 4) Menyediakan informasi yang jelas tentang beban dan tugas yang akan ditangani; 5) menyediakan waktu istirahat yang cukup agar otot-otot dapat kembali berelaksasi dan kebugaran tubuh menjadi lebih baik dalam rangka mencegah terjadinya keluhan NPB yang merupakan salah satu bagian dari gangguan otot tulang rangka akibat kerja.

\section{Usia}

Dalam penelitian ini ditemukan bahwa usia berpengaruh 4 kali menyebabkan keluhan NPB. Jadi direkomendasikan kepada manajemen perusahaan untuk: 1) Karyawan dengan usia $\geq 35$ tahun di PT.Bangkinang disubtitusi ke bagian unit kerja yang penggunaan aktivitas PBM minimal; 2) Melakukan kegiatan senam ringan secara rutin bagi karyawan untuk pencegahan terjadinya keluhan NPB.

\section{Variabel Independen yang tidak berhubungan dengan keluhan NPB \\ Kebiasaan Merokok}

Dalam penelitian ini tidak terlihat hubungan statistik signifikan antara kebiasaan merokok dengan terjadinya keluhan NPB. 


\section{KESIMPULAN}

Hasil penelitian, didapatkan proporsi keluhan NPB pada karyawan PT.PP Bangkinang Pekanbaru tahun 2016 yang adalah 61,3\% dari sampel. Variabel yang mempunyai hubungan sebab akibat dengan PBM dengan keluhan NPB pada karyawan PT.PP Bangkinang di Pekanbaru tahun 2016 yaitu postur janggal dalam PBM dan usia. Postur janggal dalam PBM berpengaruh 6 kali dan usia berpengaruh 4 kali menimbulkan keluhan NPB pada karyawan PT.PP Bangkinang Pekanbaru. Variabel confounding adalah pengerahan kekuatan otot dalam PBM dan masa kerja. Variabel yang tidak berhubungan sebab akibat dengan keluhan NPB adalah kebiasaan merokok.

\section{SARAN}

Disarankan kepada manajemen perusahaan untuk mengurangi kegiatan PBM dengan mengganti penanganan secara mekanis, melakukan pelatihan tentang teknik PBM yang aman dan benar bagi karyawan, melakukan rotasi penempatan unit kerja secara berkala.

\section{UCAPAN TERIMAKASIH}

Terimakasih yang sebesar-besarnya kepada ibu dr.Erna Tresnaningsih, MOH, PhD, Bapak Dr. Nopriadi, SKM,M.Kes, Ibu DR.Mitra,SKM.MKM, Bapak M.Kamali Zaman,SKM.MKL, yang telah memberikan dukungan, arahan, bimbingan dan masukan dalam penulisan artikel penelitian ini. Terimakasih kepada karyawan dan pimpinan PT. PP Bangkinang yang berkontribusi dalam penelitian ini.

\section{DAFTAR PUSTAKA}

Adams, R.D. (1989), Pain The Back, Neck and Extremities, In Principles of Neurology, $4^{\text {th }}$, New York: Mc Graw-Hill Information Science,

Anderson GBJ, et, Al, (1997), Musculoscletal Disorders and Workplace Factors, Collumbia: National Institute for Occupational Safety and Health,

Bindra, Supreet, (2015), Epidemiology of Low Back Pain In India Population, Vol. 5 No.1, http://www.cibtech.org/jms.htm,

Bickley, S, Lynn, (2012), Bates' Guide to Physical Examination and History Taking $7^{\text {th }}$, New Mexico: Wolters Kluwer,

Burdor A, and Jansen JP, (2003), Effect of Measurement Strategy and Stastical Analysis on doseresponse relation between physical workload and low back pain, Netherlands: Departement of Public Health, Faculty of Medicine and Health Science, Erasmus University, http://oem.bmj.com

Debeeck and Hermans, (2000), Reseach on Work-related Low Back Pain Disorders, Belgium: European Agency for Safety and Health at Work,

Fieldman, et, Al, (2001), Risk Factors for the Development of Low Back Pain in Adolencence, Vol.154 No.1, U.S.A: American Journal of Epidemiology,

Gallagher, Sean, (2008), Reducing Low Back Pain and Disability in Mining, Pittsbugrh: National Institute for Occupational Safety and Health,

Harrison's, (2005), Principiles of Internal Medicine $16^{\text {th }}$, U.S.A: Mc.Graw-Hill Companies,

Howard, Jhon, (2007), Ergonomic Guidelines for Manual Material Handling, Columbia: National Institute for Occupational Safety and Health,

Health and Safety Executive, Manual Handling Assesment Charts (the MAC tool), www.hse.gov.uk/msd/mac,

Hills, C, Everett, et, Al, (2016), Mechanical Low Back Pain, Medscape: www.emedicine.medscape.com

Health and Safety Executive, (2008), Musculoscletal Disorders Mainly Affecting the Back. http://www.hse.gov.uk

Nurmianto, Eko, (2004), Ergonomi Konsep Dasar dan Aplikasinya Edisi Kedua, Surabaya: GunaWidya,

OSHA, (2000), Ergonomics: The Study of Work,U.S: Departement of Labour,

REBA employee assessment sheet, (2004): www.ergo-plus.com

Rajesh, Raghunathan, (2013), Ergonomics Redesign of Material Handling Work System in Manufacturing Plant, ISSN 2319-8753: www.ijirset.com 
Riihimaki, H, (1991), Low Back Pain, Its origin and risk indikators, Finland: Departement of Epidemiology and Biostatistics, Institute of Occupational Heath, www.ncbi.nlm.nih.gov,

Ridley, Jhon (2008), Ikhtisar Keselaatan dan Kesehatan Kerja $3^{\text {th }}$, England: PT.Erlangga Jakarta,

Santoso, Dedik, (2006), Kapasitas angkat beban untuk pekerja Indonesia, Vol.8 No.2, Teknik Industri Universitas Kristen Petra: http://www.petra.ac.id

Tarwaka, et, Al, (2004), Ergonomi untuk Keselamatan dan Kesehatan Kerja dan Produktivitas, Surakarta: Unisba Press,

Tortora and Derricson, (2009), Principles of Anatomy and Physiology $12^{\text {th }}$, U.S.A: Wiley,

Wheeler, H, Anthony, et, Al, (2016), Low Back Pain and Sciatica, Medscape: www.emedicine.medscape.com

Widanarko, Baiduri, et, Al, (2011), Prevalence of musculosketal symptoms in relationto gender, age and occupational/Industrial group, International Journal of Industrial Ergonomics: www.elsevier.com/locate/ergon,

Waters, R, Thomas (1994) Aplications Manual for the Revised NIOSH Lifting Equation, Ohio: Departement of Health and Human Services, 